dissect the carcasses, it was possible to calculate the $\mathbf{R}^{2}$ for prediction of body composition based on the relative distribution of CT-numbers from one tomographic plane. It was possible to describe 85 p. 100 variation in energy content of the living animal. This in vivo prediction was extremely good compared to what can be obtained by other known methods.

Improved technique, Computer Tomographs more suited for scanning animals, etc. gives great possibilities for a future development of a new field in animal breeding.

\title{
The use of milk recording results on social sector farms
}

\author{
M. ŠEF \\ Agricultural Institute of Slovenia, Ljubljana, Hacquetova 2, Yugoslavia
}

In Slovenia 10000 cows are kept on 35 social sector farms. The milk recording is performed on all cows without any regard to the race, productivity, age, lactation stage, etc. After the lactation is finished, the lactation data are computed for each cow separately. At the end of the control year an annual report is made for every social sector farm according to races and lactations. Every report contains the milk and fat content in the total and standard lactation, the milk content in 100 days and per feeding day and the length of the after-calving interval and the period between the two calvings.

The cows are also classified according to their productivity and fed accordingly. Better milkcows are inseminated with the semen of better bulls, their progeny is included in the planned production.

For the development of the milk recording on the social sector farms monthly reports on the productivity of cows have been planned to improve the selection of the first calving heifers and other cows already at the beginning of the lactation. 